\title{
Rhetorical Structure of Research Articles in Agricultural Science
}

\author{
Huimin Shi ${ }^{1} \&$ Anchalee Wannaruk ${ }^{1}$ \\ ${ }^{1}$ School of Foreign Languages, Institute of Social Technology, Suranaree University of Technology, Nakhon \\ Ratchasima, Thailand \\ Correspondence: Anchalee Wannaruk, School of Foreign Languages, Institute of Social Technology, Suranaree \\ University of Technology, Nakhon Ratchasima, 30000, Thailand. Tel: 6644-224-2135. E-mail: \\ wannaruk@sut.ac.th, trchristine_shi@yahoo.com
}

\author{
Received: May 1, 2014 Accepted: June 3, 2014 Online Published: July 15, 2014 \\ doi:10.5539/elt.v7n8p1 URL: http://dx.doi.org/10.5539/elt.v7n8p1
}

\begin{abstract}
Although the rhetorical structure of research articles (RA) has been extensively examined from individual sections to complete IMRD sections regarding different disciplines, no research has been addressed to the overall rhetorical structure of RAs as a whole entity in the field of agricultural science. In this study, we analyzed 45 agricultural science RAs, using Kanoksilapatham's (2005) model as an analytical tool. A sixteen-move structure was identified, 3 for the Introduction section, 5 for the Methods section, 4 for the Results section and 4 for the Discussion section, respectively. The rhetorical structure found in this study extends and refines previous models. In particular, the occurrences of moves in the sections of Methods and Results appear to be discipline-dependent. These results seem to indicate that the rhetorical structure of agricultural science RAs tend to have their own pattern, so that this study should benefit non-native scientists in general and non-native scientists in agricultural science in particular, not only allowing them to understand RAs better, but also helping them in their competition for international publication.
\end{abstract}

Keywords: rhetorical structure, research article, move

\section{Introduction}

Concerning the dominant use of English in academic communication, Swales (1990) claimed "...there is no doubt that English has become the world's predominant language of research and publication" (p. 99). According to Gibbs (1995), most journals included in international databases, such as Science Citations Index (SCI), are published in English. In fact, over 80 percent of journal articles published internationally are written in English (Hamel, 2007), suggesting that research articles (RAs) in English play a key role in the spread of academic knowledge. Thus, the ability to publish RAs internationally is crucial for academic and professional success in science and technology.

Yet writing RAs in English has always been a daunting undertaking for non-native English speaking (NNES) researchers. Besides presenting the disciplinary content in a RA, researchers also need to meet the often stringent language requirements of the international journals concerned (Belcher, 2007; Flowerdew, 2001), whereby NNES researchers are put at a disadvantage in competing with their native English speaking (NES) peers (W. Cho, 2009; S. Cho, 2004; Flowerdew, 1999b; Huang, 2010; M. Marus 'ic' \& A. Marus `ic', 2001). This difficulty could be critical for NNES scientists, who might not succeed in being published if their work is coded in the wrong rhetorical style. To provide the most effective support to NNES academics, several dimensions concerning international publication were examined, including the attitudes of journal editors (Flowerdew, 2001), the challenges that NNES writers face (Flowerdew, 1999a, 1999b), and the perspectives held by NNES writers (Chiu, 2011), revealing that inadequate knowledge of rhetorical organization was the main difficulty faced by NNES writers. The difficulty is sometimes so frustrating that NNES writers feel marginalized, or even excluded from the international scientific community.

After John Swales' introduction of the Create A Research Space (CARS) model in 1990, there have been a great number of studies on the rhetorical structure of RAs in the past two decades, for example, Nwogu's (1997), Posteguillo's (1999), or Peacock's (2011) studies. Although these genre-based studies have made a significant contribution to the improvement of NNES academics' writing skills, a number of them have tended to focus on individual sections of the RA. These include Anthony (1999), Samraj (2002, 2005), Ozturk (2007), Hirano 
(2009), Pho (2010), Rubio (2011), Sheldon (2011) and Amnuai and Wannaruk (2013a) on the Introduction section; Lim (2006), Huang and He (2010) and Peacock (2011) on the Methods section; Brett (1994), Williams (1999) and Lim (2010) on the Results section; and Holmes (1997), Peacock(2002), Amirian, Kassaian and Tavakoli (2008), Basturkmen (2012) and Amnuai and Wannaruk (2013b) on the Discussion section. Although writers know the format of IMRD (Introduction-Methods-Results-Discussion) sections, they are unaware of the internal linking of the 4 sections (Nwogu, 1997). In fact, each section sets the stage for the following section, and collectively they contribute to form a cohesive piece of research. Despite the fact that research into the rhetorical structure of the RA as a whole entity would be highly beneficial to NNES academics, it should be noted that the RA as a whole entity has received much less attention. Until now, there have been a limited number of move analyses of RAs across all four sections.

At the same time, the rhetorical structure of RAs varies according to disciplines, for example, the investigations into a specific discipline (Nwogu, 1997, on medicine; Kanoksilapatham, 2005, on biochemistry), across disciplines (Peacock, 2011; Samraj, 2008) or even between two sub-disciplines of one field (Ozturk, 2007). This observation is in line with Zhu's (2004) comments that the discourse organization of RAs should not be taught as a uniform structure to learners with different discipline backgrounds. Again, another research gap emerged from previous studies, showing that, to date, the rhetorical structure of RAs as a whole entity in agricultural science is under-investigated, despite the fact that the individual section of Introduction section in agricultural science has already been examined (Rubio, 2011).

In view of the pedagogical needs to facilitate learners' writing and research gaps, this research aimed to make a contribution to our knowledge of the agricultural science RA genre by analyzing 45 agricultural science RAs based on Kanoksilapatham's (2005) framework. In doing so, this research attempted to help NNES agricultural science writers in their competition for international publication.

\section{Method}

\subsection{Compilation of the Corpus}

A corpus of 45 experimental RAs was compiled from 22 peer reviewed international journals in the 3 major fields of agricultural science: 15 from animal science, 15 from food science and 15 from plant science. Those journals were chosen based on the impact factor. In the selection process, the status of native speakers was not taken as a variable because papers published in those journals could be considered as a representative sample of expert writing (Pho, 2008). Finally, all 45 RAs were coded. For example, the ninth article, in the fields of animal science, food science and plant science, was referred to as A9, F9 and P9 respectively.

\subsection{Framework of Move Analysis}

Since the fields of biochemistry and agricultural science are two branches of hard science, Kanoksilapatham's (2005) framework seems to be an appropriate reference for the present investigation, particularly with regard to the systematic examination of IMRD sections. This framework was further fine-tuned because more codes have been developed to accommodate the new steps that emerged from the findings. Then, the modifications to the framework were made accordingly, yielding an accurate description of the rhetorical structure of RAs in agricultural science. Also, Kanoksilapatham (2005) gave criteria to justify the frequency of a move occurrence by claiming that the occurrence of a conventional move should be ranged from $100 \%$ to $60 \%$, whereas the occurrence of an optional move is below $60 \%$.

\subsection{Reliability of Move Analysis}

Move boundaries were identified by the function or content of texts in the present study, however, the function-based approach can be criticized for its subjectivity (Paltridge, 1994). Since Crooks (1986) and many move analysts (e.g., Kanoksilapatham, 2007; Peacock, 2002; Pho, 2008) have used independent coders to ensure a high degree of agreement in their analyses, two invited coders were involved in the coding process in the present study. One is an internationally published agricultural science professor, who is a native speaker with a $\mathrm{Ph} . \mathrm{D}$ degree. The other is a Ph.D candidate in this field as well. Then, the researcher and these 2 coders each independently coded 10 articles randomly drawn from the corpus for checking the reliability of move identifications, which reached $84.43 \%$ agreement. Any differences were resolved through discussion. After discussion, there was no disagreement.

\section{Results and Discussion}

\subsection{The Introduction Section}

The Introduction section leads readers into the article by providing brief but convincing answers to questions 
concerning the importance of the study, the relationship between the study and previous work in the area, and the objectives of the study. Three moves were observed in this section, including Move 1: Stating why the topic is important, Move 2: Preparing for the present study and Move 3: Introducing the present study as reported in Table 1.

Table 1. Frequency of moves and steps found in the Introduction section

\begin{tabular}{ll}
\hline Move/Step & Frequency $(\mathbf{N}=\mathbf{4 5})$ \\
\hline M1: Stating why the topic is important & $\mathbf{4 5}(\mathbf{1 0 0 \%}) * *$ \\
S1: Commenting on the importance of the topic & $45(100 \%) * *$ \\
S2: Making topic generalizations & $33(73 \%) * *$ \\
S3: Reviewing previous research & $45(100 \%) * *$ \\
M2: Preparing for the present study & $\mathbf{3 5}(\mathbf{7 8 \%}) * *$ \\
S1: Indicating a research gap & $35(78 \%) * *$ \\
S2: Making a hypothesis & $3(7 \%)^{*}$ \\
M3: Introducing the present study & $\mathbf{4 5}(\mathbf{1 0 0 \% )} * *$ \\
S1: Stating Purpose(s) & $41(91 \%) * *$ \\
S2: Presenting the hypothesis & $3(7 \%) *$ \\
S3: Describing procedures & $26(58 \%) *$ \\
S4: Presenting findings & $10(22 \%) *$ \\
S5: Stating the value of the present study & $5(11 \%) *$ \\
\hline
\end{tabular}

Note. $\mathrm{N}=$ the total number of analyzed RA Introduction sections in this study, $* *=$ conventional, and $*=$ optional

Move 1: Stating why the topic is important serves as an orientation for readers by establishing the significance of the research within this field. To achieve this communicative function, three variations were used as shown below:

Step 1: Commenting on the importance of the topic claims that the topic is worth conducting research by describing the significance of the study.

1) The ER plays an important role in a variety of cellular processes, including lipid and protein synthesis, protein folding, and post-translational modification of proteins (Cha et al., 2009) (P14).

Step 2: Making topic generalizations aims to generalize the topic.

2) There is growing concern that food allergies are increasing at an alarming rate for reasons that are not well understood (Gonipeta, Parvataneni, Tempelman \& Gangur, 2009) (F11).

Step 3: Reviewing previous research reviews the established and specific knowledge related to the research topic.

3) Polyethylene glycol (PEG) has been commonly used in studies to determine effects of tannins on silage preservation and animal metabolism (Villalba \& Provenza, 2002; Ben Salem et al., 2003), as PEG binds to tannins to inhibit their biological action (Oliveira, Berchielli, Reis, Vechetini, \& Pedreira, 2009) (A12).

On the whole, Move 1 provides the rationale of the study by acknowledging the importance of the research topic with a shift from general (Step 2, 73\% of corpus) to specific aspects (Step 3, 100\% of corpus). The review of literature (Step 3) can be presented with Steps 1 and 2, that is, Steps 1 and 2 were often followed by citations, functioning to provide support for claiming the significance of the study or generalizing the topic. This result is consistent with those of Samraj (2002) and Kanoksilapatham (2005), which reflect the richness of the literature in hard science.

Move 2: Preparing for the present study attempts to draw readers' attention by focusing on the inadequacy in previous research that needs new investigation or by raising a hypothesis which has emerged from previous studies, as shown below: 


\section{Step 1: Indicating a research gap}

4) Although cytosolic Hsp90 proteins have been well characterized in plants, ER-resident Hsp90 proteins are still largely unknown (Cha et al., 2009) (P14).

\section{Step 2: Making a hypothesis}

5) We hypothesized that light induction of the VAZ cycle might be mimicked by alternative elicitors; that is, there may be "cross-talk" between the lightsensing mechanisms and those of other associated stresses (Frankling \& Whitelam, 2004; Spiro et al., 2004) (Ferna'ndez-Marı'na, Balaguer, Esteban, Becerril, \& Garc1'a-Plazaola, 2009) (P8).

As expected, researchers are often motivated not just by significance of the study as reported in Move 1, Step 1 but also by research gaps, leading to the occurrence frequency of a research gap (Step 1,78\% of corpus) being far more common than the occurrence frequency of a hypothesis (Step 2, 7\% of corpus) in the present study. This is because the presence of research gaps not only reflects the value of the research but also strengthens the researcher's justification for his study.

After presenting the significance of the research topic (Move 1) and research gaps or hypothesis (Move 2), Move 3: Introducing the present study paves the way for putting forward the current research by Stating the purpose(s) of the research, Presenting the hypothesis, Describing the main features of the experimental procedure, Highlighting the main findings of the research, and Stating the value of the present study.

\section{Step 1: Stating the purpose(s) of the research}

6) The aim of the current research was to study the influence of water washing and of a treatment with PAA, 80 and $250 \mathrm{mg} \mathrm{L}^{-1}$, on the shelf-life of grated carrots as well as on their sensory quality and nutrient content (carotenoids, phenols and antioxidant capacity) throughout storage (Vandekinderen et al., 2009) (P10).

\section{Step 2: Presenting the hypothesis}

7) The overall hypothesis was that differences in miRNA levels between these 2 types of follicles would be in each case consistent with follicular roles proposed in earlier in vitro studies (Donadeu \& Schauer, 2013) (A4).

\section{Step 3: Describing the main features of the experimental procedure}

8) Additionally we measured the effect of frying on the $\delta^{2} H$-and $\delta^{18} O$-composition of meat water in meat slices (as steaks and schnitzels) (Horacek, Eisinger, \& Papesch, 2010) (F6).

\section{Step 4: Highlighting the main findings of the research}

9) The bicarbonate was determined as the bulk ${ }^{14} \mathrm{C}$ presence in plant parts and as distribution of C-tracer in ryegrass and white clover (Rasmussen, Kusliene, Jacobsen, Kuzyakov, \& Eriksen, 2013) (P11).

\section{Step 5: Stating the value of the present study}

10) Our results expand the knowledge of mechanisms associated with lignin and phenolics biosynthesis and facilitate the development of novel strawberry cultivars with nutritionally superior properties (Ring et al, 2013) (P5).

The third move is often used to conclude the Introduction sections in agricultural science. Announcement of purpose(s) of the study (Step 1) and a preview of methods (Step 3) were found to be employed in a high number of agricultural science introductions ( $91 \%$ and $58 \%$ of corpus respectively), whereas statement of findings (Step 4) was less frequent ( $22 \%$ of corpus). This can be explained by the fact that agricultural science researchers tend to report findings in the Results section in order to motivate readers to read further, meanwhile, the presence of purpose(s) (Step 1) is often used as a lead-in to the Methods section.

\subsection{The Methods Section}

After the Introduction section, the second major section, often labeled as the Methods section, describes the materials and experimental procedure employed in the study which has the function of showing the readers how the experiment was carried out. Unlike the Introduction section, very little previous research has apparently examined the individual section of Methods probably because the Methods section is highly specialized and heavily content-oriented. In this study, five moves were observed to comprise the Methods section, including Move 4: Describing materials, Move 5: Describing experimental procedures, Move 6: Detailing equipment, Move 7: Presenting equations describing the phenomena or models of the phenomena, and Move 8: Detailing statistical procedures as shown in Table 2. 
Table 2. Frequency of moves and steps found in the Methods section

\begin{tabular}{ll}
\hline Move/Step & Frequency (N = 45) \\
\hline M4: Describing materials & $\mathbf{4 5}(\mathbf{1 0 0 \% )} * *$ \\
S1: Listing materials & $45(100 \%) * *$ \\
S2: Detailing the source of the materials & $24(53 \%) *$ \\
S3: Providing the background of the materials & $21(47 \%) *$ \\
M5: Describing experimental procedures & $\mathbf{4 5}(\mathbf{1 0 0 \% )} * *$ \\
S1: Documenting established procedures & $41(91 \%) * *$ \\
S2: Describing the location where the study was conducted & $7(16 \%) *$ \\
S3: Detailing procedures & $45(100 \%) * *$ \\
S4: Providing the background of the procedures & $36(80 \%) * *$ \\
M6: Detailing equipment & $\mathbf{3 9}(\mathbf{8 7 \% )} * *$ \\
M7: Presenting equations describing the phenomena or models of the phenomena & $\mathbf{6 ( 1 3 \% ) *}$ \\
M8: Detailing statistical procedures & $\mathbf{3 4}(\mathbf{7 6 \% )} * *$
\end{tabular}

Note. $\mathrm{N}=$ the total number of analyzed RA Methods sections in this study, ${ }^{* *}=$ conventional, and $*$ optional

Move 4: Describing materials attempts to introduce the materials used in the experiment and background information related to those materials. The function of Move 4 can be realized by the following 3 steps.

Step 1: Listing materials or experimental animals includes the materials or animals used in the experiment.

11) Mature Angus-cross, nonpregnant, nonlactating, ertrous-cycling beef cows were used in these experiments (Fields, Perry, \& Perry, 2009) (A6).

Step 2: Detailing the source of the materials introduces the way the materials were obtained (e.g. being purchased or given by an organization).

12) A batch of $18 \mathrm{~kg}$ of carrots (Daucus carota L.) was obtained from a local wholesale business (Van Landschoot, Ghent, Belgium) (Vandekinderen et al., 2009) (P10).

Step 3: Providing the background of the materials describes the features of materials or gives the criteria for the selection of materials or experimental animals.

13) The Ph of these solutions was 5.74 and 4.42, respectively. The concentrations used were selected based on their effectiveness in a screening experiment (Vandekinderen et al., 2009) (P10).

As shown by previous results (e.g. biochemistry, sociology, and medical science), Move 5: Describing experimental procedures is a core move in experimental studies, occurring in 45 out of 45 articles in the present study. This move normally provides a rationale for selecting a certain experimental procedure and demonstrates that the experiment has been carried out in an appropriate way. Move 5 can be realized by the following 4 steps.

Step 1: Documenting established procedures is helpful for future researchers to replicate or modify the study.

14) Clinical scoring (on a scale of 0 to 5) was performed by 2 individuals according to the method described previously (Li et al. 2000) (Gonipeta, Parvataneni, Tempelman, \& Gangur, 2009) (F11).

Step 2: Describing the location where the study was conducted presents a description of the location of a farm or an experimental field where the study takes place.

15) Field studies were conducted at the Experimental Farm of Faculdade de Ciencias Agrarias a Veterinarias-UNESP, Brazil, 21ำ $155,48^{\circ} 19^{\prime} E$, 605m attitude, from November 2002 to June 2003 (Ferenc akovic et al., 2012) (A13).

Step 3: Detailing procedures describes the steps performed in a logical and sequential manner.

16) Groups of mice ( $n=5-10$ per group) were exposed to saline (100 uL per mouse per application) or milk whey protein (1 $\mathrm{mg}$ and $2.5 \mathrm{mg}$ per mouse per application) (Gonipeta, Parvataneni, Tempelman, \& Gangur, 2009) (F11). 
Step 4: Providing the background of the procedures presents the analysis of an experimental procedure and criteria of a certain procedure or comments on a whole experiment.

17) The procedure followed within this study showed some differences with the procedure practically used: the treatment with $250 \mathrm{mg} L^{-1} P A A$ exceeds the limit value advised by the FDA and no after-rinsing step was included in the experiment (Vandekinderen et al., 2009) (P10).

In the present study, the rhetorical structure of the Methods section is also characterized by the identification of the location of a study (Step 2) probably because agricultural science experiments take place mostly on farms instead of labs with activities such as feeding animals or growing plants. To allow future researchers to replicate the experiment, the description of the established procedure (Step 1,91\% of corpus), the experimental procedure (Step 3,100\% of corpus) and the background of the procedure (Step 4, $80 \%$ of corpus) is much more common than a description of the location of the study (Step 2, 16\% of corpus).

Move 6: Detailing equipment emphasizes information related to the apparatus, such as the name of the manufacturer, for the purpose of replication and to facilitate the identification of procedures. Such information, presented in $87 \%$ of the agricultural science corpus, was at a much higher frequency rate than that in previous studies (e.g. Kanoksilapatham, 2005; Nwogu, 1997). The frequent use of Move 6 in the current study was due to the fact that the experiment might not be correctly replicated if an agricultural science researcher uses the wrong equipment.

18) Finnigan MAT 251 and Finnigan Delta $+X L$, each of which was coupled to an automatic equilibration device equipped with pneumatic values (manufacturer: Finnigan and Parcom) (Horacek, Eisinger, \& Papesch, 2010) (F6).

Move 7: Stating equations describing the phenomena or models of the phenomena is used to predict variables in the experiments, being identified in 6 out of 45 articles.

19) The objective function of mate selection is the cumulative discounted performance (CDP), which is calculated as: (Nishio, Kahi, \& Hirooka, 2010) (A15).

$$
C D P=\sum_{t-1}^{h} \frac{\sum_{i=1}^{3}\left(M S_{i, t} g_{i}+F S_{i, t} g_{i}\right)}{(1+d r)^{t-1}}
$$

Another striking difference between the Methods section in the field of agricultural science and other disciplines (e.g. Pho, 2008; Posteguillo, 1999; Peacock, 2011) is that agricultural science researchers are more likely to use a mathematical model in the study, whereas researchers in those disciplines do not. The reason for this is explained as follows: a mathematical model is an accurate description of a system, showing the idea of how things work in a way that agricultural researchers can predict. This leads to a comparison between the predictions and the experimental data. Thus, it is usually necessary to include mathematical modeling procedures in agricultural research with the facilitation of computer technology (Thornley \& France, 2007).

Move 8: Detailing statistical procedures aims at analyzing data and testing the research hypothesis formulated in the Introduction section with $76 \%$ occurrences in agricultural corpus. Conversely, Kanoksilapatham (2005) observed that this move occurred in only $13.32 \%$ of biochemistry corpus. The difference might be attributed to the nature of agricultural productivity and food safety, which might be heavily conditioned by uncertainty, for example, climate factors, and biological and ecological processes. To reduce this uncertainty, statistical tools have been applied to deal with the study of such uncertain phenomena and to test the hypothesis concerning the relationship of different variables involved in an experiment.

20) Data were subjected to multi-way ANOVA to determine which factors (treatment or storage time) mostly influence the response variable (microbial parameter, sensory attribute and nutrient content) and whether an important interaction exists between treatment and storage time (Vandekinderen et al., 2009) (P10).

\subsection{The Results Section}

Like the Methods section, the Results section is also one of the sections which have received little attention. However, it plays a crucial role in research, aiming to report the results of a study in an accurate, unbiased, and complete manner. This section is made of 4 moves, including Move 9: Stating procedures, Move 10: Justifying procedures or methodology, Move 11: Stating results and Move 12: Commenting on the results as shown in Table 3. 
Table 3. Frequency of moves and steps found in the Results section

\begin{tabular}{ll}
\hline Move/Step & Frequency (N = 45) \\
\hline M9: Stating procedures & $\mathbf{3 2}(\mathbf{7 1 \%}) * *$ \\
S1: Describing aims and purpose(s) & $20(44 \%)^{*}$ \\
S2: Making hypotheses & $5(11 \%)^{*}$ \\
S3: Listing procedures or research methodologies & $23(51 \%) *$ \\
M10: Justifying procedures or methodology & $\mathbf{1 3 ( 2 9 \% ) *}$ \\
S1: Detailing methods (similar to these) that people used before & $10(22 \%)^{*}$ \\
S2: Commenting on whether the methods yielded successful results & $10(22 \%) *$ \\
M11: Stating results & $\mathbf{4 5 ( 1 0 0 \% ) * *}$ \\
M12: Commenting on the results & $\mathbf{3 9}(\mathbf{8 7 \%}) * *$ \\
S1: Explaining reasons why these results occur & $27(60 \%) * *$ \\
S2: Making generalizations or interpretations of the results & $32(71 \%) * *$ \\
S3: Evaluating the current findings against those from previous studies & $16(36 \%) *$ \\
or with regard to the hypotheses & $7(16 \%) *$ \\
S4: Stating limitations & $9(20 \%) *$ \\
S5: Summarizing &
\end{tabular}

Note. $\mathrm{N}=$ the total number of analyzed RA Results sections in this study, ${ }^{*}=$ conventional, and $*=$ optional

Move 9: Stating procedures explains why and how the data have been produced, consisting of 3 steps as follows: Step 1: Describing aims and purpose(s) restates objectives before presenting data obtained in the experiment; Step 2: Making hypotheses is used to present the hypotheses; and Step 3: Listing procedures or research methodologies provides the readers with information about procedures or research methodologies.

Move 9 functions to give a smooth transition from the Introduction and Methods sections to the Results section, by restating the aims of the study, research hypotheses and experimental procedure before presenting the results of the study. Interestingly, to realize the function above, the co-occurrence of Move 9, Steps 1 and 3 were observed in 14 out of 45 articles.

21) To determine number of copies of T-DNA, (Move 9, Step 1) the genomic DNA was digested with EcoRI and the blot was probed with the $1.1 \mathrm{~kb}$ Xhol digest of the plasmid pCAMBIA 1305.1 which is the hph gene fragment. (Move 9, Step 3) (Kuriakose, Arun, Gnanamanickam, \& Thomas, 2009) (P13).

Move 10: Justifying procedures or methodology enables readers to understand the acceptability of the procedures concerned. Move 10 can be presented in the following 2 steps.

Step 1: Detailing methods (similar to these) that people used before justifies a particular procedure by citing established knowledge of this procedure.

22) The genome walking technique which we refer to as random amplification of genomic end (RAGE) is a well-demonstrated tool for the isolation and cloning of genomic regions flanking a known sequence. (Kuriakose, Arun, Gnanamanickam, \& Thomas, 2009) (P13).

Step 2: Commenting on whether the methods yielded successful results accounts for the justfication of a particular method by evaluating the successful results yielded by such a method.

23) The method has been previously used by other groups to isolate other promoters from other plants [14-16]. We have also used this method to isolate a stress inducible promoter from different species of wild rices in a separate study. In our experience, this is an excellent method for the isolation for promoters from plants (Kuriakose, Arun, Gnanamanickam, \& Thomas, 2009) (P13).

The presence of Move 10, Justifying methodology, appears to be a specific characteristic of the Results section in agricultural science and biochemistry because this was not observed in other studies on this section, such as in social science (Brett, 1994), computer science (Posteguillo, 1999), medical science (Williams, 1999) or applied linguistics (Yang \& Allison, 2003). As explained by Thompson (1993, cited in Kanoksilapatham, 2005), the 
occurrence of Move 10 indicates the degree of acceptability of the results by claiming that results are obtained from a justifiable methodology.

Move 11: Stating results highlights the expected results by translating the numerical data into written text, being identified in 100\% of corpus. Unlike Brett's (1994) and William's (1999) findings, the present study was only observed to report substantiating findings, indicating that agricultural scientists do not present all the observations occurring in the experiments. On the contrary, they just report those observations which are important for their research purposes.

24) Figure 4 shows the allele frequencies among animals sold over the planning horizon. In all cases, the allele frequencies remained constant for 2 years as a result of the increase in the frequency of the favourable allele in animals for replacement (Nishio, Kahi, \& Hirooka, 2010) (A15).

Move 12: Commenting on the results presents claims based on the results, being realized by the following five steps: Step 1: Explaining reasons why these results occur gives the explanations to account for the results; Step 2: Making generalizations or interpretations of the results frames the comments on the significance of the result; Step 3: Evaluating the current findings against those from previous studies or with regard to the hypotheses serves to show the similarities or differences of the findings by comparing them with those from previous studies; Step 4: Stating limitations and Step 5: Summarizing summarizes the findings of the study.

The analysis of Move 12 shows that most steps found in this move are similar to the comment categories in Brett's (1994) model, except for 2 major differences. First, Brett's step of "Evaluation of Findings re: Hypotheses" was not found in this corpus of agricultural science. Second, the additional step of "Stating limitations" was identified in this investigation. In particular, the step of "Stating limitations" is used to remind readers of some factors potentially affecting the results of the data analysis, suggesting that future research could be improved by avoiding those potential factors mentioned earlier. This step was found 7 times and can be used to avoid any possible doubts on the results of the study.

In order to gain the readers' acceptance of their findings as a part of the contribution to the field of research, agricultural science writers attempt to give reasons for their findings or to put their findings in the context of previous studies. Thus, Move 11 was found to be the most cyclical one in this section, combining with Move 12, Steps 1, 2 and 3. These results are in agreement with other studies (e.g. Posteguillo, 1999; Williams, 1999 and Yang \& Allison, 2003) showing that the Results section is not only where new findings are highlighted but also where they may be interpreted and commented on, often in a cyclical fashion.

\section{Move 11: Stating results and Move 12, Step 1: Explaining reasons why these results occur}

25) The initial $\delta^{18} O$ values in the minced pork and the chunks of pork were -4.9 and $-5.6 \%$, respectively (Fig.2). (Move 11) This difference in the initial values is explained by the minced pork and the pork chunks having been taken from different carcasses (Move 12, Step 1) (Vandekinderen et al., 2009) (P10).

\section{Move 11: Stating results and Move 12, Step 2: Making generalizations or interpretations of the results}

26) After $5 d$ of storage the score for flavor was exceeding the acceptability limit (Move 11). In conclusion, a treatment with $250 \mathrm{mg} \mathrm{L}^{-1} P A A$ affected the sensory quality of grated carrots by a change in texture and the development of a sour taste and odor, even in the early stage of the shelf-life (Move 12, Step 2) (Kuriakose, Arun, Gnanamanickam, \& Thomas, 2009) (P13).

\section{Move 11: Stating results and Move 12, Step 3: Evaluating the current findings}

27) The exonic sequences of SPATA 1 were monomorphic in the tested stallions (Move 11) and identical to the reference sequence of the horse genome assembly EquCab 2.0 (Move 12, Step 3) (Giesecke, Hamann, Stock, Woehlke, Sieme, \& Distl, 2009) (A3).

\subsection{The Discussion Section}

The Discussion section discusses the results presented in the Results section by evaluating them and interpreting their implications. Since this section requires critical reading on the part of readers, it is thought to be the most important section in the RA, and therefore the most troublesome to write (Flowerdew, 1999a). Four moves were observed in this section, including Move 13: Contextualizing the study, Move 14: Consolidating results, Move 15: Stating the limitations of the present study and Move 16: Suggestions for further research as shown in Table 4. 
Table 4. Frequency of moves and steps found in the Discussion section

\begin{tabular}{|c|c|}
\hline Move/Step & Frequency $(\mathrm{N}=45)$ \\
\hline M13: Contextualizing the study & $39(87 \%)^{* * *}$ \\
\hline S1: Stating what is already known from previous studies & $34(76 \%)^{* *}$ \\
\hline $\begin{array}{l}\text { S2: Detailing conclusions, claims, deductions or research gaps } \\
\text { based on analysis from previous studies }\end{array}$ & $27(60 \%)^{* *}$ \\
\hline S3: Stating aims or hypothesis of the study & $19(42 \%)^{*}$ \\
\hline M14: Consolidating results & $45(100 \%)^{* * *}$ \\
\hline S1: Restating the methodology & $32(71 \%)^{* *}$ \\
\hline S2: Stating selected findings & $43(96 \%)^{* *}$ \\
\hline S3: Referring to previous literature & $42(93 \%)^{* *}$ \\
\hline S4: Explaining results or differences in findings & $36(80 \%)^{* *}$ \\
\hline S5: Making overt claims or generalizations & $42(93 \%)^{* *}$ \\
\hline S6: Exemplifying & $6(13 \%)^{*}$ \\
\hline S7: Stating the value of the study & $10(22 \%)^{*}$ \\
\hline M15: Stating the limitations of the present study & $25(56 \%)^{*}$ \\
\hline S1: Limitations of the findings & $10(22 \%)^{*}$ \\
\hline S2: Limitations of the methodology & $10(22 \%)^{*}$ \\
\hline S3: Limitations of the claims made & $7(16 \%)^{*}$ \\
\hline S4: Limitations of previous studies & $7(16 \%)^{*}$ \\
\hline M16: Suggestions for further research & $19(42 \%) *$ \\
\hline
\end{tabular}

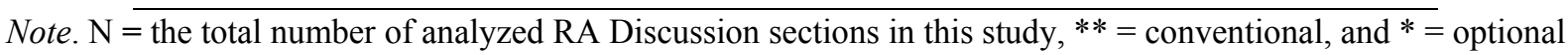

Move 13: Contextualizing the study announces how important the study is by framing the context of the study, hence, drawing readers' attention to the report or discussion of results that follows.

Step 1: Stating what is already known from previous studies justifies the preference of a particular method in the study by illustrating specific information from previous studies.

28) Crossbreeding is carried out to develop new breeds or types from foundation purebreds and to introgress genes and characteristics from one breed to another (Dickerson 1969). It is widely used in commercial animals to exploit heterosis (Swan \& Kinghorn, 1992; Freyer et al., 2008) (Nishio, Kahi, \& Hirooka, 2010) (A15).

Step 2: Detailing conclusions, claims, deductions or research gaps based on analyses from previous studies

29) One previous study using $B A L B / c$ mice and a cholera toxin adjuvant approach reported that $B A L B / c$ mice are "genetically resistant" to milk allergy (Morafo et al., 2003). In contrast, others reported that BALB/c mice could develop an allergic response to milk following oral exposure to milk protein along with cholera toxin adjuvant (Adel-Patient et al., 2005) (Gonipeta, Parvataneni, Tempelman, \& Gangur, 2009) (F11).

Step 3: Stating the aims or hypothesis of the study

30) The primary objective of the current study was to evaluate the impact of a decontamination step with PAA on all quality aspects of grated carrots during storage, including physiological responses, microbial proliferation and spoilage, sensory quality and nutrient content (Vandekinderen et al., 2009) (P10).

Move 14: Consolidating results is the most elaborate move in the Discussion section. This move can be realized by 5 steps, including Step 1: Restating the methodology, Step 2: Stating selected findings, Step 3: Referring to previous literature, Step 4: Explaining results or differences in findings (differences between 2 sets of data in the current paper, for example, treatment A vs. treatment B, or differences between results in this paper and in the previous literature), Step 5: Making overt claims or generalizations, Step 6: Exemplifying, and Step 7: Stating the value of the study.

Similar to the Results section, different steps in Move 14 were found to be combined, for instance, the 
co-occurrence of Move 14, Steps 2 and 3; Move 14, Steps 4 and 3 and Move 14, Steps 5 and 3 were found in 20 out of 45,16 out of 45 and 14 out of 45 articles, respectively. These combinations demonstrate that agricultural science researchers place great emphasis on making results interesting and less demanding for readers.

\section{Move 14, Step 2: Stating selected findings and Step 3: Referring to previous literature}

31) DgHsp90 strongly suppressed the heat-induced aggregation of MDH and CS. (Move 14, Step 2) This folding activity of DgHsp90 is a distinct function of molecular chaperones [29]. (Move 14, Step 3) (Cha et al., 2009) (P14).

\section{Move 14, Step 4: Explaining differences in findings and Move 14, Step 3: Referring to previous literature}

32) One reason could be that domestic pigs are bred and raised in intensive conditions where transmission of Y.enterocolitica from positive animals to negative animals is unavoidable. (Move 14, Step 4) It has been shown that a specialized fattening pig production system with intensive raising conditions have the highest prevalence for Y.enterocolitica in pigs (Skjerve et al., 1998) (Move 14, Step 3) (Fredriksson-Ahomaa, Wacheck, Koenig, Stolle, \& Stephan, 2009) (F4).

Move 14, Step 5 Making overt claims or generalizations and Move 14, Step 3: Referring to previous literature

33) The way $250 \mathrm{mgL}^{-1}$ PAA is suppressing the PAL-activity is not fully understood, but possibly the low $\mathrm{pH}$ induced in the surface tissue played an important role in the inhibition of PAL-activity (Ruiz-Cruz et al., 2007b) (Move 14, Steps 5 \& 3) (Vandekinderen et al., 2009) (P10).

The co-occurrence of different steps in Move 14 shows that linking outcomes (Step 2), explanations (Step 4) or claims (Step 5) with previous studies (Step 3) is much more frequent than other move combinations in the Discussion section. Presumably, it is important in the field of agricultural science to place findings in the context of previously published research in this section.

Move 15: Stating the limitations of the present study functions to make readers aware of the conditions under which the study was conducted, thus making them cautious not to overgeneralize the findings. This move points out the limitations of the findings, of the methodology, of the claims made and of previous studies.

\section{Step 1: Limitations of the findings}

34) However, the presence of outliers in Experiment 1 shows that hydrogen isotopes might be less reliable in "non-ideal" storage conditions (Horacek, Eisinger, \& Papesch, 2010) (F6).

\section{Step 2: Limitations of the methodology}

35) This does also mean that in the case of a significant association of one SNP, the other SNPs are not necessarily significantly associated with the trait analyzed (Giesecke, Hamann, Stock, Woehlke, Sieme, \& Distl, 2009) (A3).

\section{Step 3: Limitations of the claim made}

36) In the case of Arabidopsis, however, the expression of the GUS gene was throughout the anther tissue and, therefore, the expression was not tapetum-specific in the strictest sense. However, sectioning of the tiny Arabidopsis flowers was a very difficult task and the picture may not be the most accurate (Kuriakose, Arun, Gnanamanickam, \& Thomas, 2009) (P13).

\section{Step 4: Limitations of previous studies}

37) We are not aware of any published estimates of genetic correlations between residual feed intake and separate fat accumulations at the different sites of pork carcasses (Hoque, Katoh, \& Suzuki, 2009) (A9).

Move 16: Suggestions for further research is used to give some recommendations for further studies based on drawing limitations or deductions from the research, that is, Move 16 usually coexisted with limitations of the study (Move15) or claims or generalizations of the findings (Move 14, Step 5). In addition, the occurrence frequency of this move varied in different disciplines, $42 \%$ in the present study, $70 \%$ in applied linguistics corpus (Amnuai \& Wannaruk, 2013 b), 53.33\% in biochemistry corpus (Kanoksilapatham, 2005) and 40\% in medical science corpus (ElMalik \& Nesi, 2008). Elimination of this move is used to avoid scientific competition (Berkenkotter \& Huckin, 1995, cited in Posteguillo, 1999). Perhaps the reason for the various occurrence frequencies in different corpora is related to the level of competition for research space in different fields.

38) Here, we directly demonstrate this possibility in BALB/c mice. (Move 14, Step 5) Consequently, we suggest that future investigations on human milk allergy consider transdermal exposure to milk protein as a possibility in 
the pathogenesis of milk allergy in humans (Move 16) (Gonipeta., Parvataneni, Tempelman, \& Gangur, 2009) (F11).

39) In the case of Arabidopsis, however, the expression of the GUS gene was throughout the anther tissue and therefore, the expression was not tapetum-specific in the strictest sense. However, sectioning of the tiny Arabidopsis flowers was a very difficult task and the picture may not be the most accurate. (Move 15, Step 3) It would be, therefore, important to study the promoter in a direct plant with larger anthers with a very clearly demarcated tapetum to obtain a clearer picture (Move 16) (Kuriakose, Arun, Gnanamanickam, \& Thomas, 2009) (P13).

\section{Conclusion}

The objective of the study was to investigate the rhetorical structure of agricultural science RAs using Kanoksilapatham's (2005) model. The results obtained in this study show that a typical agricultural science RA appears to be made up of 16 moves, consisting of 3 from the Introduction section, 5 from the Methods section, 4 from the Results section and 4 from the Discussion section, respectively. Yet it should be noted that the moves and steps observed in each section do not occur in a linear sequence, that is, one move can occur more than once and be realized by different steps. Also, the results of the present study seem to indicate that the rhetorical structure of agricultural science RAs has its own pattern in terms of moves/steps identified and move/step frequencies. These variations particularly occurred in the sections of Methods and Results, including Move 5, Step 1, Move 6, Move 7, Move 8, Move 10 and Move 11, confirming Swales' comments that "the major differences do not lie so much in Introductions and Discussions (where I believe most people would expect it) but rather in the Methods and Results sections" (Swales, 1990, pp. 175-176).

With some further refinements to the modifications presented here, this study is expected to benefit both NNES agricultural science writers and ESP/EAP practitioners as well. By mapping out the move structure in all four sections of a target genre, this study will provide insight into the scientific RA genre in general and, in particular, agricultural science RAs neglected by genre analysts. NNES agricultural science writers will find the comprehensive descriptions of the move structure a useful aid in constructing RAs. In a similar vein, detailed and comprehensive delineations of the characteristics of this genre will provide ESP/EAP practitioners with useful information for syllabus design and materials development.

However, due to the limitations of this study, some recommendations are suggested for further study. Since the structural organizations presented in the study were obtained from only 45 RAs, further research is needed to analyze more RAs in order to yield more conclusive findings. In addition, the present study revealed that the move structure varied across disciplines so further analyses can also be extended to contrastive rhetoric or studying cultural variations in generic structure. In other words, further studies could investigate the differences by comparing English agricultural science RAs published in local journals with those published in international journals. Such comparative studies may yield more interesting results, then the rhetorical structure of agricultural science RAs will become more visible to NNES writers due to a greater awareness of the differences.

\section{References}

Amirian, Z., Kassaian, Z., \& Tavakoli, M. (2008). Genre analysis: An investigation of the discussion sections of applied linguistics research articles. The Asian ESP Journal, 4(1), 39-63.

Amnuai, W., \& Wannaruk, A. (2013a). An analysis of moves in introductions in international and Thai journal research articles. PASAA, 45, 61-90.

Amnuai, W., \& Wannaruk, A. (2013b). Investigating move structure of English applied linguistics research article discussions published in international and Thai journals. English Language Teaching, 6(2), 1-13.

Anthony, L. (1999). Writing research article introductions in software egineering: How accurate is a standard model? IEEE Translations on Professional Communication, 42(1), 38-46.

Basturkmen, H. (2012). A genre-based investigation of discussion sections of research articles in Dentistry and disciplinary variation. Journal of English for Academic Purposes, 11, 134-144.

Belcher, D. D. (2007). Seeking acceptance in an English-only research world. Journal of Second Language Writing, 16(1), 1-22.

Brett, P. (1994). A genre analysis of the results section of sociology articles. English for Specific Purposes, 13(1), 47-59.

Chiu, Y.-H. (2011). Exploring non-native science scholars' perspectives of writing for publication in English. The Asia-Pacific Education Researchers, 20(3), 469-476. 
Cho, D. W. (2009). Science journal paper writing in an EFL context: The case of Korea. English for Specific Purposes, 28, 230-239.

Cho, S. (2004). Challenges of entering discourse communities through publishing in English: Perspectives of nonnative-speaking doctoral students in the United States of America. Language, Dentity and Education, $3(1), 47-72$.

Crookes, G. (1986). Towards a validated analysis of scientific text structure. Applied Linguistics, 7(1), 57-70.

ElMalik, A. T., \& Nesi, H. (2008). Publishing research in a second language: The case of Sudanese contributors to international medical journals. Journal of English for Academic Purposes, 7, 87-96.

Flowerdew, J. (1999a). Writing for scholarly publication in English: The case of Hong Kong. Journal of Second Language Writing, 8(2), 123-145.

Flowerdew, J. (1999b). Problems in writing for scholarly publication in English: The case of Hong Kong. Journal of Second Language Writing, 8(3), 243-264.

Flowerdew, J. (2001). Attitudes of journal editors to nonnative speaker contributions. TESOL Quarterly, 35(1), $121-150$.

Gibbs, W. (1995). Trends in scientific communication: Lost science in the third world. Scientific American, August, 76-83.

Hamel, R. E. (2007). The dominance of English in the international scientific periodical literature and the future of language use in science. AILA Review, 20, 53-71.

Hirano, E. (2009). Research article introductions in English for specific purposes: A comparison between Brazilian Portuguese and English. English for Specific Purposes, 28, 240-250.

Holmes, R. (1997). Genre analysis, and the social sciences:An investigation of the structure of research article discussion sections in three disciplines. English for Specific Purposes, 16(4), 321-337.

Huang, J. C. (2010). Publishing and learning writing for publication in English: Perspectives of NNES PhD students in science. Journal of English for Academic Purposes, 9, 33-44.

Huang, P., \& He, L. (2010). Contrastive genre analysis of research methods in English and Chinese experimental research articles. The Asian ESP Journal, special edition (conference proceedings), 126-136.

Kanoksilapatham, B. (2005). Rhetorical structure of biochemistry research articles. English for Specific Purposes, 24, 269-292.

Kanoksilapatham, B. (2007). Rhetorical moves in biochemistry research articles. In D. Biber, U. Connor, \& T. A. Upton (Eds.), Discourse on the move: Using corpus analysis to describe discourse structure (pp. 73-119). Amsterdam: John Benjamins.

Lim, J. M.-H. (2010). Commenting on research results in applied linguistics and education: A comparative genre-based investigation. Journal of English for Academic Purpose, 9, 280-294.

Lim, J. M. H. (2006). Method sections of management research articles: A pedagogically motivated qualitative study. English for Specific Purposes, 25, 282-309.

Marus`ic', M., \& Marus`ic', A. (2001). Good editorial practice: Editors as educators. Croatian Medical Journal, $42,113-120$.

Nwogu, K. N. (1997). The medical research paper: Structure and functions. English for Specific Purposes, 16(2), 119-138.

Ozturk, I. (2007). The textual organisation of research article introductions in applied linguistics: Variability within a single discipline. English for Specific Purposes, 26, 25-38.

Paltridge, B. (1994). Genre analysis and the identification of textual boundaries. Applied Linguistics, 15(3), 288-299.

Peacock, M. (2002). Communicative moves in the discussion section of research articles. System, 30(4), 479-497.

Peacock, M. (2011). The structure of the methods section in research articles across eight disciplines. Asian ESP Journal, 7(2), 99-124.

Pho, P. D. (2008). How can learning about the structure of research articles help international students? In T. McGrath (Ed.), Conference Proceedings of the 19th ISANA International Education Conference, 2-5 
December 2008, paper 14.

Pho, P. D. (2010). Linguistic realizations of rhetorical structure: A corpus-based study of research article abstracts and introductions in applied inguistics and educational technology. In S. T. Gries, S. Wulff, \& M. Davies (Eds.), Corpus-linguistics Applications: Current Studies, New Directions (pp. 135-152). Amsterdam: Editions Rodopi B.V.

Posteguillo, S. (1999). The Schematic Structure of Computer Science Articles. English for Specific Purposes, 18(2), 139-160.

Rubio, M. M. D. S. (2011). A pragmatic approach to the macro-structure and metadiscoursal features of research article introductions in the field of agricultural sciences. English for Specific Purposes, 30, 258-271.

Samraj, B. (2002). Introductions in research articles: Variations across disciplines. English for Specific Purposes, 21, 1-17.

Samraj, B. (2005). An exploration of a genre set: Research article abstracts and introductions in two disciplines. English for Specific Purposes, 24, 141-156.

Samraj, B. (2008). A discourse analysis of master's theses across disciplines with a focus on introductions. Journal of English for Academic Purposes, 7, 55-67.

Sheldon, E. (2011). Rhetorical differences in RA introductions written by English L1 and L2 and Castilian Spanish L1 writers. Journal of English for Academic Purpose, 10, 238-251.

Swales, J. M. (1990). Genre analysis: English in academic and research settings. Cambridge: Cambridge University Press.

Thornley, J. H. M., \& France, J. (2007). Mathematical models in agriculture: Quantitative methods for the plant, animal and ecological sciences (2nd ed.). Cambridge: CABI.

Williams, I. A. (1999). Results sections of medical research articles: Analysis of rhetorical categories for pedagogical purposes. English for Specific Purposes, 18(4), 347-366.

Yang, R., \& Allison, D. (2003). Research articles in applied linguistics: Moving from results to conclusions. English for Specific Purposes, 22, 365-385.

Zhu, W. (2004). Faculty views on the importance of writing, the nature of academic writing, and teaching and responding to writing in the disciplines. Journal of Second Language Writing, 13, 29-48.

\section{Copyrights}

Copyright for this article is retained by the author(s), with first publication rights granted to the journal.

This is an open-access article distributed under the terms and conditions of the Creative Commons Attribution license (http://creativecommons.org/licenses/by/3.0/). 